\title{
Ley Orgánica de Defensa del Consumidor y el Marketing Digital
}

\section{Organic Law for the Defense of the Consumer and Digital Marketing}

\author{
Paola Estefanía Albán Trujillo. ${ }^{1}$, Gabriela Paola Carrasco Lara. ${ }^{2}$ \& Susana Alexandra \\ Yánez Cuadrado. ${ }^{3}$
}

DOI: https://doi.org/10.33262/visionariodigital.v5i3.1774

\begin{abstract}
.
The Organic Law of Consumer Defense establishes the right to consumer protection that arises from the need to solve the problems that modern consumption represents in the face of digital marketing in the commercialization of products and services through online stores located on digital platforms. It is of great interest for consumers to know the veracity and transparency of the information and thus adherence to the effectiveness of the regulations embodied in advertising through what is mentioned as characteristics, terms and conditions of marketing. In this sense, the objective of this research is to examine marketing measures applied to digital marketing, the digital media used for commerce and the effectiveness of the Organic Law for the Defense of the Consumer. This research is framed within a methodological approach of comparative legal, legal and historical analysis, with a design and level of non-experimental and documentary bibliographic research, respectively. The analysis was oriented on the main digital media selected for the commercialization of products and services, identifying customer and company advantages - B2C (Business-to-Consumer) in which organizations focus their products and services to the customer / end consumer; so also in the norm that regulates consumer - supplier relationships. The investigation will get to know the most used social media for digital commerce, inferring that there are a large number of consumers who are

\footnotetext{
${ }^{1}$ Universidad Estatal de Bolívar, Facultad de Ciencias Administrativas Gestión Empresarial e Informática. Guaranda, Ecuador, palban@ueb.edu.ec. https://orcid.org/0000-0001-8311-5767

${ }^{2}$ Universidad Estatal de Bolívar, Facultad de Ciencias Administrativas Gestión Empresarial e Informática. Guaranda, Ecuador, gcarrasco@ueb.edu.ec. https://orcid.org/0000-0002-4635-1418

${ }^{3}$ Universidad Estatal de Bolívar, Facultad de Ciencias Administrativas Gestión Empresarial e Informática. Guaranda, Ecuador, syanez@ueb.edu.ec. https://orcid.org/ 0000-0001-5407-7909
} 
the object of deceptive marketing. It was concluded that, in Ecuador, the Organic Law of Consumer Defense protects consumers and penalizes suppliers of products or services that fail to comply with their offer, which allows demonstrating that the legal norm is effective.

Keywords: Consumer Protection, Digital Marketing, Law, Regulatory Effectiveness.

\section{Resumen.}

Introducción. La Ley Orgánica de Defensa del Consumidor establece el derecho de protección al consumidor que nace ante la necesidad de solucionar los problemas que representa el consumo moderno frente al marketing digital en la comercialización de productos y servicios a través de tiendas online ubicadas en plataformas digitales. Es de gran interés para los consumidores conocer la veracidad y transparencia de la información y con ello el apego a la efectividad de la normativa plasmada en la publicidad a través de lo que se menciona como características, términos y condiciones de comercialización. Objetivo. En tal sentido el objetivo de la presente investigación es, examinar medidas de comercialización aplicadas al marketing digital, los medios digitales utilizados para el comercio y la efectividad de la Ley Orgánica de Defensa del Consumidor. Metodología. Esta investigación se enmarca en un enfoque metodológico de análisis histórico, teórico jurídico y jurídico comparado, con un diseño y nivel de la investigación no experimental y bibliográfico documental respectivamente. El análisis se orientó en los principales medios digitales seleccionados para la comercialización de productos y servicios, identificando ventajas de cliente y empresa - B2C (Business-to-Consumer) en el que las organizaciones enfocan sus productos y servicios al cliente/consumidor final; así también en la norma que regula las relaciones consumidor - proveedor. Resultados. La investigación permitió conocer los medios sociales más utilizados para el comercio digital, inferir que existe un gran número de consumidores que son objeto de marketing engañoso. Conclusión. Se concluyó que, en el Ecuador, la Ley Orgánica de Defensa del Consumidor, protege a los consumidores y sanciona a los proveedores de productos o servicios que incumplen su oferta lo que permite demostrar que la norma legal es efectiva.

Palabras claves: Efectividad Normativa, Ley, Marketing Digital, Protección al Consumidor.

\section{Introducción.}

\section{La Ley del Consumidor}

El derecho de protección del consumidor nace ante la necesidad de solucionar los problemas que representa el consumo moderno, esto se debe a la falta de conocimiento, experiencia y planificación adecuada del consumidor, así como no controlar el gasto y promover el consumo responsable. Para el año de 1977 el Consejo Supremo de Gobierno, expidió la Ley de Control de Precios y Calidad, en la cual principalmente en el Art. 17, se estableció la obligación de publicar en las respectivas etiquetas de cada producto, las 
características de calidad, estableciéndose de esta forma los organismos encargados del control de precios y calidad, entre los que encontramos a los ministerios, municipalidades, intendencias, subintendencias y comisarías.

Con estos antecedentes durante el gobierno del Dr. Rodrigo Borja, bajo el ideal de dotar de una protección específica y propia a los consumidores, se promulgó la primera ley sobre la materia, la Ley de Defensa del Consumidor, como un cuerpo normativo que reunió varias concepciones, iniciativas y leyes que de forma indirecta protegían al consumidor ya que se encontraban dispersas en otros cuerpos legales (Consuelo, 2015).

En septiembre de 1970 mediante Decreto Supremo 357, R.O. 54, se encarga al INEN la verificación del cumplimiento de normas técnicas oficializadas por el Ministerio de Industrias como obligatorias. Posteriormente, con el Decreto Supremo No. 965, R.O. 376 de 24 de agosto de 1973 se regula la publicidad de bebidas alcohólicas y cigarrillos. El siguiente antecedente de trascendencia lo encontramos en la Ley de Defensa del Consumidor, publicada el 12 de septiembre de 1990, Registro Oficial 520, norma con limitaciones y escasa aplicación, sin embargo, con ella se elimina el sistema de control de precios (Martinez, 2005).

Esta Ley tiene como objetivo regular las relaciones entre proveedores y consumidores motivando el conocimiento y protegiendo el derecho de los consumidores, también incentivando la equidad, la seguridad jurídica en las relaciones entre las partes antes mencionadas (La Ley Orgánica de Defensa del Consumidor, 2019). Toda persona natural o jurídica que como destinatario final adquiera, maneje o disfrute bienes o servicios, o bien reciba oferta para ello. Todo habitante se transforma en consumidor a partir de su origen, debido a que, usa productos o servicios que son adaptados como propios sin necesidad de desearlos. Se nace como habitante, se crece como consumidor, al llegar al mundo una persona se transforma en cierta medida de un conjunto objetivo, en un consumidor o potencial consumidor (Gabriel, 2017). El derecho del consumidor nació con el objeto de llevar protección al débil jurídico.

La defensa de los intereses de los consumidores y usuarios constituye, en la actualidad, una de las preocupaciones de la sociedad, que se ha traducido en la proliferación de una sucesión de normas jurídicas tendentes a la protección del individuo, posible adquiriente de un bien o servicio, y de los intereses difusos como respuesta a una serie de fenómenos socio-económicos que han ido operando en el mercado y con sus consecuencias políticas. (Veintimilla, 2011)

Su antecedente radica en la situación de subordinación y minusvalía en que se encuentra colocado el hombre moderno al interactuar con los proveedores de bienes de consumo, el cual está integrado por un conjunto de organismos jurídicos específicos, desarrollados para prevenir actitudes de menoscabo de los derechos del consumidor (Ovalle Favela, 1993). 


\section{Los consumidores tienen los siguientes derechos:}

En la Ley Orgánica de Defensa del Consumidor de nuestro país, podemos encontrar los siguientes derechos:

- Protección de la vida, salud y seguridad en el consumo de bienes y servicios.

- Que proveedores públicos y privados oferten bienes y servicios competitivos de óptima calidad, y a elegirlos con libertad.

- Recibir servicios básicos de óptima calidad.

- Contar con información adecuada, veraz, clara, oportuna y completa sobre los bienes y servicios ofrecidos en el mercado.

- Trato transparente, equitativo y no discriminatorio o abusivo por parte de los proveedores de bienes o servicios. Protección contra la publicidad engañosa o abusiva, a métodos comerciales coercitivos o desleales.

- Educación del consumidor, orientada al fomento del consumo responsable y a la difusión adecuada de sus derechos.

\section{Como consumidor también tiene algunas responsabilidades que cumplir:}

- Propiciar y ejercer el consumo racional y responsable de bienes y servicios.

- Preocuparse de no afectar el ambiente mediante el consumo de bienes o servicios que puedan resultar peligrosos en ese sentido.

- Evitar cualquier riesgo que pueda afectar la salud y vida, así como la de los demás, por el consumo de bienes o servicios lícitos.

- Informarse responsablemente de las condiciones de uso de los bienes y servicios a consumirse (Coba, 2019).

Responsabilidad de los Consumidores según el Presidente de Consumers International Anwar Fazal, en el año 1980, convocó a las diferentes organizaciones que integran el movimiento de consumidores y planteó la introducción de un conjunto de responsabilidades que los consumidores deben acatar para hacer cumplir sus derechos.

"Todos estos principios son importantes para varias organizaciones de derechos del consumidor en la actualidad"

Conciencia crítica: Los consumidores deben realizar un análisis acerca de la recepción, calidad de servicios y bienes.

Participación o acción: Los consumidores deben participar activamente para que reciban un trato justo.

Responsabilidad social: Las acciones de los consumidores deben tener responsabilidad social, preocupación por el comportamiento hacia el impacto de sus acciones sobre las demás personas, la relación con los grupos vulnerables de la comunidad, con las realidades económicas y sociales existentes. 
Responsabilidad ecológica: El consumidor debe ser consciente del impacto que produce sus decisiones de consumo sobre el medio ambiente físico, considerar el aspecto ecológico y la conservación de la naturaleza como el factor más importante en la mejora de la calidad real de vida de la sociedad para el presente y el futuro del planeta.

Solidaridad: Las mejores acciones se producen mediante esfuerzos de colaboración dirigidos a la formación de organizaciones de consumidores, pues juntos tienen la capacidad y la fuerza para ayudarse.

\section{El marketing en un escenario digital}

Al marketing directo y sus vías de vías de comunicación se las llama hoy en día tradicionales o 0.0 , en la etapa 1.0, surge la página web como exhibición online y logra su tráfico al obstaculizar al usuario con banners mientras explora en páginas de noticias u otras. Con el surgimiento de la etapa web 2.0 o web social, las compañías se muestran al diálogo con los compradores, los agentes intermediarios desaparecen casi dejando de ser necesarios, debido a que las redes sociales otorgan la posibilidad a cualquier usuario anunciar contenido para que estos se muestren a la audiencia potencial, entra en uso el social media marketing y con este la interacción como un paso anterior a la venta, es por ello que ser digital no es lo único, también hay que ser social.

$\mathrm{Al}$ conocido marketing 2.0 le alcanza el 3.0 que se orienta más a los sentidos que a la razón, no como hacían sus antecesores; entonces y bajo este escenario las empresas giran la vista hacia los usuarios dinámicos en las redes sociales, se interesan y los ven como un medio para darse a conocer, así nacen los influencers, ya no reporteros, siendo usuarios normales, pero con un sinnúmero de seguidores a quienes los distinguen como referentes por lo que se dejan influir al momento de comprar, es así que el marketing de influencers se une a los procedimientos de comercialización digital como herramienta precisa en actividades relacionadas con tecnología y moda, utilizado en lanzamiento de productos o promoción de eventos (Sanagustín, 2016).

La manera de comunicarse dejó de ser unidireccional para ser bidireccional, más activa, las Redes Sociales se han tornado los nuevos escaparates de las marcas, siendo el medio donde se manifiestan gustos e intereses, así como también inquietudes sugerencias y hasta descontentos. Este tipo de comunicación moderna se trasladó al Marketing tradicional, induciendo una relación inmediata entre proveedor/consumidor, donde el único intermediario es el Community Manager (CM) a través de las Redes Sociales. Para las marcas, actualmente contar con un buen Community Manager es esencial, porque se requiere alcanzar gran interacción con sus clientes a través de los canales digitales y con ello dominar esta significativa estrategia de comunicación, es por ello que la figura del $\mathrm{CM}$ toma relevancia en las empresas, porque no solo se encarga de comunicar la imagen de la marca, sino que es un gestor de la imagen corporativa en su conjunto.

En la actualidad el internet es, para las empresas, el canal primordial de ventas, un canal importante de comunicación, publicidad, difusión y referencia, las magnas compañías de consumo masivo, vestimenta y servicios, han tenido que adecuar los modelos de negocios 
a nuevas maneras de comprar, vender y de ofertar sus productos y/o servicios para poder mantenerse en mercados globales, esto manifiesta que las plataformas digitales no son el futuro, son el presente y están adecuados no solo a las generaciones nuevas, sino que van incluyéndose cada vez más en los grupos etarios de adultos mayores, la sencillez y tendencia que brinda la digitalización y su conectividad ha hecho el traslado mucho más rápido (Zuccherino, 2016).

Los dispositivos móviles se han transformado en elementos muy valiosos para enlazar con consumidores actuales y potenciales, los smartphones han reformado las prácticas de consumo y comportamiento frente a productos o servicios, otorgando gran utilidad como es, utilizar el móvil en una tienda para cotejar precios entre distintos establecimientos o para analizar las opiniones de los consumidores antes de seleccionar el producto a adquirir. El ahorro de tiempo y dinero más la disminución de riesgos al decidir una compra son los elementos primordiales de esta práctica (Martínez, et al. 2015).

El objeto del social media es promover la interacción entre individuos instaurando, anunciando e intercambiando el conocimiento con la intervención de las colectividades digitales, y estar enterados de todos los acontecimientos cambios y tendencias de las regiones y del mundo. El social media está combinado por distintas plataformas digitales en las que se amplía el impacto social de la comunicación boca a boca, es por ello que muchas marcas utilizan estos medios sociales para darse a conocer y posicionarse, buscando potenciar la empresa con miras a obtener resultados medibles y rentables (Shum Xie, 2019).

\section{Metodología.}

A fin cumplir con las metas propuestas en la presente investigación, se propone examinar las medidas de comercialización aplicadas al marketing digital y su grado de eficacia en comparación a la Ley Orgánica de Defensa del Consumidor, se realizó un estudio contextualizado de la normativa, utilizando técnicas cualitativas, con el fin de recaudar la mayor información, ejecutando un análisis de fuentes documentales primarias y secundarias, con el propósito de interpretar a cabalidad lo implícito en el derecho positivo, enfocando el estudio principalmente en la normativa y su régimen de aplicación en materia comercial y sus implicaciones.

Métodos teóricos a emplear:

Análisis histórico: Se aplicó con el propósito de obtener fuentes de información primaria que permitan acentuar la investigación desde sus orígenes.

Teórico - Jurídico: Se utilizó a través de un análisis sobre la filosofía jurídica básica fundamental (Doctrina), brindando mayor importancia y realce jurídico.

Jurídico - Comparado: Método también conocido como: micro comparación o análisis marco comparativo, estará presente en la investigación a través del estudio de la información obtenida, con la finalidad de realizar un símil de resultados, buscando la homologación de algunos aspectos y la detección de problemas. 
Se aplicó un diseño y nivel de la investigación no experimental y bibliográfico documental respectivamente, el estudio se enfoca en la recolección de datos estadísticos que permitan estudiar la eficacia del marketing digital, permitiendo la posibilidad de un estudio comparativo y una exposición de realidades, utilizando métodos como: análisis crítico a la doctrina y la jurisprudencia, además de la aplicación de métodos analíticos, teóricos y jurídicos.

\section{Resultados.}

La investigación revela que los medios sociales de comercialización como redes sociales y las tiendas online ofrecen todo tipo de productos y servicios a un vasto campo de consumidores en el que se encuentran personas de todas las edades, y que acceden con gran facilidad a lo que buscan, aunque la publicidad que ven y/o escuchan no siempre es exacta o semejante a lo que reciben.

El universo del comercio electrónico es tan activo y versátil lo que exige en sus actividades a tener en cuenta las tendencias de las nuevas prácticas de consumo de los compradores para orientar los esfuerzos hacia el éxito. En la actualidad las redes sociales son comparadas con una plaza física; es el lugar a donde recurre la gente y por lo tanto donde se pueden identificar oportunidades de negocio, cada vez se incrementa el número de personas que las utilizan, funcionan en paralelismo del comercio electrónico. Las redes sociales impulsan la viralidad de las tiendas en línea, los actores del comercio electrónico facilitan imágenes y vídeos de los productos y servicios para que puedan ser compartidos en redes buscando impulsar el contenido y abriendo la oportunidad de que sus mismos clientes también los compartan la información para atraer a nuevos usuarios y potenciales compradores.

Al presente, la utilización de dispositivos móviles es particularmente importante, principalmente para las empresas dedicadas al marketing online, y estas acciones son atendidas con mucho entusiasmo por los usuarios, es notoria la importancia que están alcanzando los Smartphone y las tabletas para vender, además, la integración de un negocio offline con el comercio electrónico, es posible y rentable, funcionan las compras por Internet y recogen el producto en la tienda física, o a través del Internet ofrecen cupones de descuento y los canjean en la tienda convencional, entendiéndose como una forma de lograr el incremento de visitas en la tienda offline y de esta manera también las posibilidades de venta, cada canal debe estar caracterizado, de forma que se le permita utilizar sus fortalezas y reducir sus debilidades (Nieto, 2014).

El Internet es un canal de venta eficaz otorgando a los negocios la posibilidad de incrementar el volumen de ventas respecto a años anteriores, en todas las organizaciones es pertinente desplegar y fortificar la oferta del e-commerce, puesto que abarca la distribución, venta, compra, mercadeo y suministro de información de productos y/o servicios mediante el Internet, sensatos de estar a la evolución permanente de mercados globales, cada empresario debe ver el Internet como el medio de desarrollo y crecimiento para su negocio, ingresar en el comercio electrónico es una gran oportunidad para que las 
empresas aumenten sus volúmenes de ventas y participación en el mercado (Arenal, 2016).

La tendencia actual y el uso de las tiendas virtuales representa el traslado de la actividad operativa comercial tradicional de un comercio cotidiano al Internet, como se presenta en la tabla 1, en este escenario, hay que tener en cuenta que pueden suscitarse conflictos y reclamaciones de clientes, por ello es recomendable considerar como un factor clave para el éxito empresarial el dar al cliente la mayor importancia y conservar con él una correspondencia que lo convenza de la eficacia del servicio, fundamentalmente cuando está de por medio algún desacuerdo, para concebir su punto de vista, en casos de diferencias de valoración, lo oportuno es ubicarse en su lugar y tratar de pensar como él. La legislación vigente en Ecuador asigna al consumidor una sucesión de derechos, uno destacable es el derecho a la correcta información sobre la oferta de productos y servicios, a la atención de tramitación y reclamos. (Viciana, 2011).

TABLA 1.

CARACTERIZACIÓN EN EL E-COMMERCE

$\begin{array}{ccc}\text { Líneas de Productos y } & \text { Ventajas del B2C } \\ \text { Servicios } & \text { Empresa a Consumidor } & \begin{array}{c}\text { Medios Digitales } \\ \text { de } \\ \text { Comercialización }\end{array}\end{array}$

Tecnología

Medicamentos

Productos

Belleza

Alimentos

Médicos

Educativos

Servicios

Hoteleros

Viajes

\section{Para el cliente}

Datos oportunos de estado de compras. Comparación ágil de precios.

Oportunidad de consulta de información precisa. (catálogos electrónicos) Adquirir a distancia, sin requisito de movilización.

Adquisiciones más módicas.

\section{Para la empresa}

Mínimo importe de infraestructura.

Facilidades en el manejo de stocks.

Máximo beneficio del talento humano en el departamento de compras.

\author{
Redes Sociales \\ Facebook \\ Instagram \\ Tik Tok
Tiendas Online
Mercado Libre
Amazon
OLX
eBay
Alibaba


Esparcimiento geográfico del mercado.

Facilidades en el

proceso de compras y

ventas.

Elaborado por: Investigadores

Cuando se habla de marketing digital, se requiere considerar las disposiciones legales vigentes, con la finalidad de respetar los derechos de los consumidores, así en caso de alimentos, se cumple las disposiciones sobre rotulado mínimo, es decir, aquella información sobre el alimento, como el nombre del producto, la marca, la identificación del lote, la razón social de la empresa, el contenido neto, el número de registro sanitario, el valor nutricional, la fecha máxima de consumo, los ingredientes, el precio de venta al público, el país de origen y si el alimento es artificial, irradiado o genéticamente modificado.

Otra área en la que generalmente se cumple la normativa legal, es la relacionada a la venta de medicamentos, pues encontramos diariamente en los medios digitales, estos productos que contienen el rotulado mínimo establecido para su comercialización, entre la información más relevante encontramos el nombre del producto genérico o de marca, el contenido neto, el número de registro sanitario, la fecha de expiración y las contraindicaciones, comparado esto con las singularidades de los productos tecnológicos ofertados fácilmente se establece que estos últimos no cumplen con los paramentos que determina la ley, al adquirir equipo tecnológico no se encuentran leyendas que garanticen que el proveedor cumpla con las deficiencias de fabricación y/o funcionamiento, aunque si bien se insertan las leyendas "garantía", en tanto no se especifica en qué consisten, tampoco se determinan las condiciones en que deben hacerse efectivas, ni el lugar al cual debe acudir el consumidor para ejercerlas.

Dentro de la información básica que deben contener los productos de belleza se encuentran los componentes, cantidad y contraindicaciones que al comparar con el marketing digital no reflejan especialmente las indicaciones adversas resultantes de la utilización entre las más frecuentes: Alergias, prurito, dermatitis, daños que pueden inclusive llegar a ser permanentes. El servicio hotelero y de viajes que se oferta en los medios digitales de comercialización deben entregar al consumidor información clara, suficiente, completa, veraz y oportuna a fin se pueda realizar una selección acorde a las características que busca el cliente de acuerdo a sus necesidades y recursos lo que al ser comparado con la realidad no siempre se cumplen derivándose conflictos civiles y penales.

Los bienes y servicios controlados que son ofertados por diferentes medios digitales, deben someterse al cumplimiento de control de calidad, normas técnicas, instructivos y otros, para garantizar su calidad.

Ciertamente el marketing digital ayuda a vender servicios y productos, pero muchas veces induce al engaño, pues el consumidor es fácil de cautivar por lo bonito o lo que atrae, es 
decir, por los colores, las formas o palabras estratégicas como "gratis", “descuentos", "promoción", sin considerar las características o especificaciones que le ofrecen, además porque casi siempre el consumidor no lee, solo echa un vistazo y toma una decisión en segundos; así, una vez que realiza la adquisición y la recibe se percata que no cumple las expectativas creadas, es ahí en donde se genera el sentimiento de decepción y estafa.

Las sanciones que contempla esta Ley van desde sanciones pecuniarias, comiso de bienes o suspensión del derecho a ejercer actividades en áreas de prestación de servicios o publicidad, hasta la indemnización, reparación, reposición y devolución, según el caso, por los daños y perjuicios ocasionados, dejando a salvo, las acciones civiles, penales o administrativas a que hubiere lugar.

Las disposiciones contenidas en la Ley Orgánica de Defensa del Consumidor, son claras, concordantes y de fácil cumplimiento, lo que hace posible que los derechos de los consumidores se cumplan a cabalidad y que el marketing digital, medio más utilizado en el mundo para el comercio, no sea utilizado para engañar o estafar.

La legislación ecuatoriana contempla derechos para los consumidores y establece sanciones para la variedad de infracciones que se producen en la venta de productos o servicios, así cuando la publicidad es engañosa o abusiva, la Ley Orgánica de Defensa del Consumidor establece una multa de mil a cuatro mil dólares americanos, además de otras sanciones que pueden consistir en suspensión de la difusión publicitaria, obligar a la rectificación del contenido errado en los medios, espacios y horarios en que fueron realizados.

Al tratarse de servicios, si resultan ineficaces, defectuosos, causan daño o no se ajusten a lo estipulado, los proveedores deberán indemnizar y restituir los valores a los consumidores, además de cancelar la multa de cincuenta a quinientos dólares de los Estados Unidos de América, sanciones que hacen posible que el consumidor tenga total respaldo jurídico en las compras o servicios que adquiere.

La Dra. María Rivas menciona: El Defensor del Pueblo, está encargado de defender a los ciudadanos ecuatorianos en el territorio nacional frente a los atropellos que ellos reciban de las autoridades y funcionarios públicos, de la deficiente prestación de servicios públicos y privados y demás situaciones de las cuales es responsable el Estado. En definitiva, la Defensoría del Pueblo es la Institución de control superior que la consideró una ventanilla receptora de quejas y un cuartel de operaciones en defensa de los consumidores. (Falconí, 2015)

La Defensoría del Pueblo del Ecuador recepta las denuncias de inconformidad que presentan los consumidores como se aprecia en la siguiente tabla por años. 
TABLA 2.

PROCEDIMIENTOS SUMARIOS ATENDIDOS POR LA DEFENSORÍA DEL PUEBLO EN ATENCIÓN A LA DEFENSA DEL CONSUMIDOR

\begin{tabular}{ccc}
\hline Periodo & Peticiones & Resueltos \\
\hline año 2017 & 5.400 & 5.558 \\
\hline año 2018 & 6.246 & 5.259 \\
\hline año 2019 & & 3.952 \\
\hline
\end{tabular}

Fuente: Defensoría del Pueblo, Informes de Rendición de Cuentas.

Como se presenta en la Tabla II, en el año 2017 se resolvieron 5.558 procedimientos sumarios, que incluye trámites de años anteriores; se puede notar como del 2017 al 2018 hay un incremento en el número de casos, lo que indica que el público conoce y confía en la ley y solicita apoyo a la defensoría del pueblo, eso mismo se espera siga incrementándose, pero no se conoce la información completa hasta el momento.

Al ser verificadas las singularidades del producto y no coincidir con la publicidad digital, se puede presentar una denuncia, en virtud del amparo que le proporciona la Ley Orgánica de Defensa del Consumidor, mediante la cual se faculta al Defensor del Pueblo la protección de los derechos del consumidor.

La Ley Orgánica de Defensa del Consumidor, no hace distinción de la clase de publicidad, simplemente refiere en su Art. 6 "Quedan prohibidas todas las formas de publicidad engañosa o abusiva, o que induzcan a error en la elección del bien o servicio que puedan afectar los intereses y derechos del consumidor", disposición legal que protege al consumidor de los posibles artificios utilizados por el marketing digital.

El Ecuador es un país que rápidamente se ha ido acoplando al entorno digital, así consumidores por un lado y empresas por otro, están utilizando este medio para el comercio, aunque aún existe cierto grado de desconfianza de usuarios que al realizar pagos deben hacerlo vía internet y en ocasiones son objeto de estafas, acción que también es sancionada por la ley.

\section{Conclusiones.}

- El marketing digital actualmente es uno de los medios más utilizados para la comercialización de infinidad de productos y servicios que se ofertan en plataformas digitales como son las Redes Sociales y Tiendas Online.

- La existencia de la norma hace que el marketing digital cumpla con los requisitos establecidos para cada producto o servicio con la finalidad de proteger integralmente al consumidor, detalla características, componentes, medidas, peso y otros necesarios para singularizarlos.

- La Ley Orgánica de Defensa al Consumidor es eficiente, pues cumple con su objeto, normar las relaciones entre consumidores y proveedores; y, sancionar las infracciones que en ella se establecen, además el consumidor al presentar un reclamo por inconformidad del producto o servicio recibido es amparado por la 
ley para hacerlo y para que sea restituido su pago, entregando un producto sin defectos o un servicio de buena calidad, acción que la realiza a través de la Defensoría Pública; la efectividad de la ley se verificó a través de la investigación de los casos presentados y resueltos por esta institución.

\section{Referencias bibliográficas.}

Arenal Laza, C. (2016). Venta online (UF0032). Logroño, Spain: Editorial Tutor Formación. https://elibro.net/es/ereader/bibliotecaueb/44211?page $=8$.

Coba, K. D. (2019). Conoce tus derechos y obligaciones como consumidor. Gestion digital.

Consuelo, M. C. (2015). El Consumidor en el Marco Constitucional y el Ejercicio Efectivo de. Universidad Central del Ecuador Facultad de Jurisprudencia, Ciencias Políticas y Sociales, 25-32.

Gabriel, A. W. (2017). Consumidor y su Desconocimiento en la Sociedad Ecuatoriana. Consumidor y su Desconocimiento en la Sociedad Ecuatoriana.

Falconí, J. G. (23 de Marzo de 2015). Violación a los Derechos del Consumidor

Trámite de Quejas. Obtenido de derechoecuador.com:

https://www.derechoecuador.com/violacion-a-los-derechos-del-

consumidortramite-de-quejas--

La Ley Orgánica de Defensa del Consumidor. (06 de Mayo de 2019). Registro Oficial Suplemento116. Quito, Ecuador.

Martinez, D. (2005). https://repositorio.uasb.edu.ec/bitstream/10644/2470/1/T0346MDE-Mart\%c3\%adnez-La\%20protecci\%c3\%b3n\%20jur\%c3\%addica.pdf. Quito.

Martínez Polo, J. M. Martínez Sánchez, J. y Parra Meroño, M. C. (2015). Marketing digital: guía básica para digitalizar tu empresa. Barcelona, Spain: Editorial UOC. Recuperado de https://elibro.net/es/ereader/bibliotecaueb/57864?page=176.

Nieto Aguilar, W. G. (2017). LOS DERECHOS DEL CONSUMIDOR Y SU DESCONOCIMIENTO EN LA SOCIEDAD ECUATORIANA. . Prisma Social [en linea], 30.

Ovalle Favela, J. (1993). Derechos del Consumidor. Madrid: Reus-Madrid.

Sanagustín, E. (2016). Vender más con marketing digital. Bogotá, Ecoe Ediciones.

Shum Xie, Y. M. (2019). Marketing digital: navegando en aguas digitales (2a. ed.). Bogotá, Ediciones de la U.

Veintimilla, C. Z. (2011). EL ARBITRAJE DE CONSUMO COMO ALTERNATIVA DE SOLUCIÓN DE CONFLICTOS EN MATERIA DE DEFENSA AL CONSUMIDOR. Revista Juridica UCSG, 1. 
Viciana Pérez, A. (2011). Venta online (UF0032). Málaga, Spain: IC Editorial. Recuperado de https://elibro.net/es/ereader/bibliotecaueb/54121?page=144.

Zuccherino, S. (2016). Social Media Marketing: la revolución de los negocios y la comunicación digital. Buenos Aires, Temas Grupo Editoria

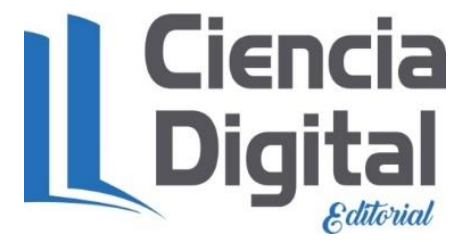




\section{PARA CITAR EL ARTÍCULO INDEXADO.}

Albán Trujillo, P. E., Carrasco Lara, G. P., \& Yánez Cuadrado, S. A. (2021). Ley Orgánica de Defensa del Consumidor y el Marketing Digital. Visionario Digital, 5(3), 88101. https://doi.org/10.33262/visionariodigital.v5i3.1774

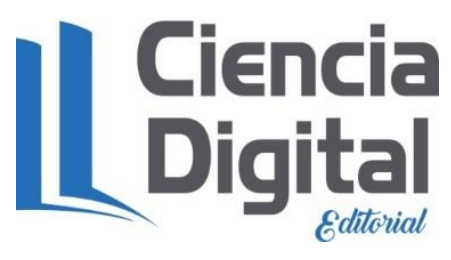

El artículo que se publica es de exclusiva responsabilidad de los autores y no necesariamente reflejan el pensamiento de la Revista Visionario Digital.

El artículo queda en propiedad de la revista y, por tanto, su publicación parcial y/o total en otro medio tiene que ser autorizado por el director de la Revista Visionario Digital.
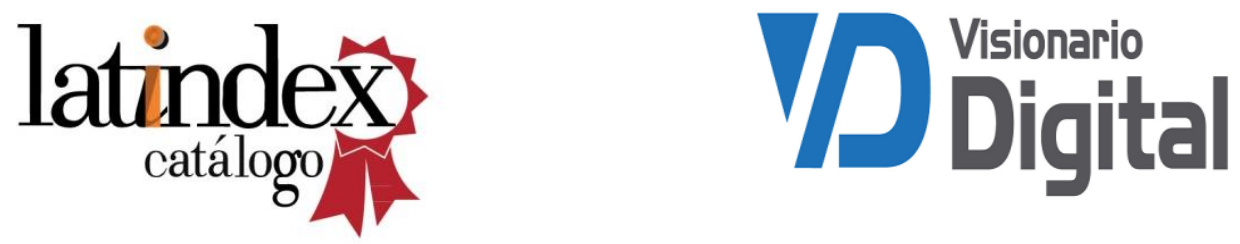